\title{
A Review on Recognition of Explosives using Calixarene
} \section{Framework}

\author{
Mansi Panchal 1(D), Keyur D. Bhatt 1,*(D), Krunal Modi ${ }^{1}{ }^{(\mathbb{D})}$, Manthan Panchal 2(D) \\ 1 Faculty of Science, Department of Chemistry, Ganpat University, Kherva, 384012, Mehsana, Gujarat, India \\ 2 Department of Chemistry, School of Sciences, Gujarat University, Ahmedabad-380009, Gujarat, India \\ * Correspondence: kdb01@ ganpatuniversity.ac.in; (Keyur Bhatt.);
}

Scopus Author ID 55258010600

Received: 20.04.2021; Revised: 1.06.2021; Accepted: 5.06.2021; Published: 27.06.2021

\begin{abstract}
In terms of social security and support, quick, ultra-sensitive, and ultra-selective detection of explosives is urgently needed around the world. This review is ardent to calixarene a recent selective and sensitive explosive sensor. The structural binding properties of the Calix system and macromolecules can be modified by various structural mode changes and interactions, and multiple possibilities of functionalization of the calixarene make these versatile molecules in the phenomena of specific recognition. This study reflects on the use of fluorescence-based chemosensors for explosive detection that has been mentioned in the literature. From this review, it is implied that calixarene excellently complexes with high selectivity explosives and attraction associated with other simple ion receptor applications using different ions.
\end{abstract}

Keywords: calixarene; analyte; explosive; chemosensor; host-guest interaction.

(C) 2021 by the authors. This article is an open-access article distributed under the terms and conditions of the Creative Commons Attribution (CC BY) license (https://creativecommons.org/licenses/by/4.0/).

\section{Introduction}

For the rapid, sensitive, ultra-selective detection of explosives, 'Quick and reliable Calixarene based Chemosensor' plays a significant role in the military venture, national defense, forensic investigations, and environmental and human well-being [1-6]. The explosive is made up of a combination of reducing and oxidizing agents that, when activated, will undergo a strongly exothermic reaction, resulting in gaseous materials that can kill people [7]. Nitroaromatic compounds are common explosives, but they are also considered environmental pollutants in the areas where they're made and handled [5]. Trinitro aromatic concentrations in groundwater and soil surrounding an exploded explosively can exceed 500 parts per billion (ppb) and 1000-5000 parts per million (ppm), respectively [8]. When TNT is digested or inhaled, it can cause skin irritation, kidney disease, and irregular liver functions [5]. TNT also has a detrimental impact on male fertility and is now considered a significant human carcinogen [9]. As a result, the US Environmental Protection Agency (EPA) has imposed a TNT cap in drinking water of $2 \mathrm{ppb}[5,9]$. Face irritation, yellow-tinged hair and skin, body fatigue, and muscle discomfort are among the health risks associated with exposure to such explosives [10$15]$. 


\section{Recognition methods}

Trained coonhounds, metal detectors, and ion mobility spectrometry (IMS) are now widely appropriate technologies for explosive detection. However, coonhound training is costly, and dogs quickly wear out from constant sensing, making it unsuitable for widespread and long-term tracking [16]. IMS is a widely used explosive detection device in air stations, with specificity down to nanograms or picograms for typical explosives. However, this technique lacks sufficient sensitivity for various explosives, such as PETN and RDX, limiting its overall effectiveness. Furthermore, IMS is inappropriate for real-time field detection because it requires complex protocols, time-consuming calibration, and poor portability and high cost [17].

A range of instrumental techniques is currently available for the purpose of explosives detection; these include GC- MS, Raman spectroscopy, X-ray imaging, nuclear quadrupole resonance, thermal and fast neutron analysis, ion mobility spectrometry, and various spectroscopic methods. Metal detectors are an indirect method that is very effective for detecting landmines and weapons contained in metals. However, they are not susceptible to the chemical fingerprint properties of explosives. They, therefore, cannot be used for transit site screening [17].

Optical approaches, which have many advantages over other common detection strategies, such as low cost, portability, high sensitivity, and selectivity, are especially appealing and promising solutions. As a result, the main target of many newly designed optical sensors for explosive detection is absorbance (colorimetric) and fluorescence responses [3]. As compared to absorbance-based techniques, fluorescence-based detection is usually one to three orders of magnitude more effective and has broader linear ranges. Furthermore, a fluorescence method's source and detector may be conveniently combined into a portable device for explosives detection in the field. As a result, the fluorescence-based approach holds much promise for rapid, sensitive, and selective explosive detection. These include photo-induced electron transfer (PET), fluorescence (Fçrster) resonance energy transfer (FRET), excimer/exciplex formation or extinction, and photo-induced charge transfer (PCT).

Importantly, the most recent advancements in this area have been structured into a concise outline that intends to rationally outline the various techniques and enhancements in the use of fluorescent material for explosive detection.

Calixarenes are attractive host compounds possessing large uncharged rings and an inherent hollow cavity-like architecture [18,19]. Such macrocyclic compounds have conformational preferences due to the ease with which they can be chemically modified, which is favorable for the complexation of different analytes. The cup-shaped cavity of calixarenes, along with the functionalized backbone (organic moieties), will provide selectiveness and extra binding sites for analytes [18,20,21]. Recent work has been summarized with a focus on the research in the recent 5 years.

Recently, Panchal et al. designed new structural motifs based on oxacalix[4]arene appended N-(3-bromopropyl) phthalimide moiety, $\mathrm{FON} 3 \mathrm{PPh}$, and $\mathrm{PON} 3 \mathrm{PPh}$, and examined their fluorogenic activities against nitroaromatic explosives. FON3PPh has a linear concentration range of $5 \mathrm{M}$ to $4.5 \mathrm{mM}$ for 4-NT, with a detection limit of $2.4 \mathrm{M}$, and a linear concentration range of $0.5 \mathrm{M}$ to $5 \mathrm{mM}$ for 2,6-DNT, with a detection limit of $0.1 \mathrm{M}$ [22]. FON3PPh and PON3PPh have binding abilities for 4-NT and 2,6-DNT of $1.15 \times 104 \mathrm{M}^{-1}$ and 
$3.02 \times 104 \mathrm{M}^{-1}$, respectively [23,24]. They studied anti-proliferative action using a cell cytotoxic assay [25-28].

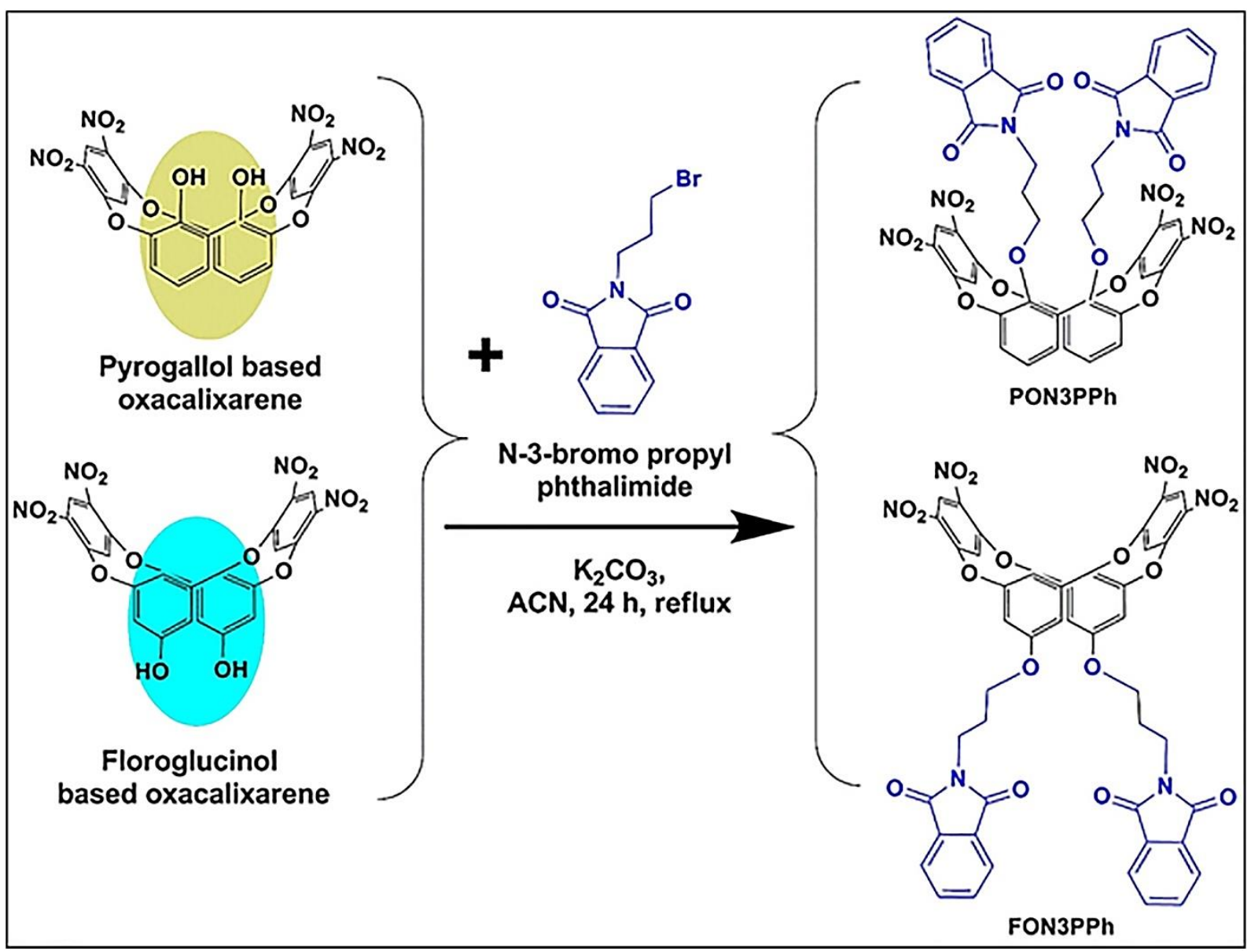

Figure 1. Synthetic route for the preparation of $\mathrm{PON} 3 \mathrm{PPh}$ and $\mathrm{FON} 3 \mathrm{PPh}$.

Rao et al. have developed a 1,3-Di-naphthalimide Conjugate of Calix[4]arene as a Sensitive and Selective Sensor for Trinitrophenol by conjugating an upper rim of calixarene with a tetrapyrenyl moiety. Two other control molecules tetraphenylhydroxy benzene (R1) and p-pyrenyl-hydroxy benzene (R2), were synthesized to best understand the function of the calix[4]arene platform and pyrenyl moieties in $\mathrm{R}$ that lacks the calix[4]arene platform. The $\mathrm{R}$ exhibits high sensitivity to TNP in tetrahydrofuran (THF) over eleven other nitroaromatic compounds (NACs) studied by exhibiting significant fluorescence enhancement, indicating that it is selective to TNP over the other NACs.[29]. On the other hand, control molecules R1 and R2 suggest that a calixarene platform and a tetrapyrenyl moiety in the receptor system are needed for TNP selective sensing. Fluorescence titration and isothermal titration calorimetry have been used to study TNP binding to R. The numerical calculations revealed the existence of TNP complexation by $\mathrm{R}$, with the data revealing TNP entrapment by two adjacent pyrene moieties through stacking interaction. The mobility of the pyrene moieties present in $\mathrm{R}$ should be limited due to such host-guest complexation. The 1H NMR spectral analysis indicates that TNP binding decreases the stability of the pyrenyl moieties of R, which serves as additional evidence for the complexation. TNP sensing by R has been demonstrated in THF solution, on the surface of a silica gel, and on the surface of cellulose paper, with the lowest detection threshold (LODs) of $1.5,3.5$, and $6.5 \mathrm{M}$, respectively.

LOD of 2.1 mole was observed in a solid mixture of $\mathrm{R}$ and TNP. Because supramolecular aggregation of $\mathrm{R}$ is expected to depend on the guest species, the corresponding 
details were investigated using microscopy techniques such as scanning electron microscopy, atomic force microscopy, transmission electron microscopy, and significant changes in $\mathrm{R}$ aggregation upon interaction with TNP were observed. The observed fluorescence enhancement is due to this aggregation. As a result, the tetrapyrenyl calix[4]arene conjugate (R) serves as a sensitive and reliable platform for detecting TNP in a mixture of nitroaromatic compounds (NACs) with different fluorescence intensities [30-35].

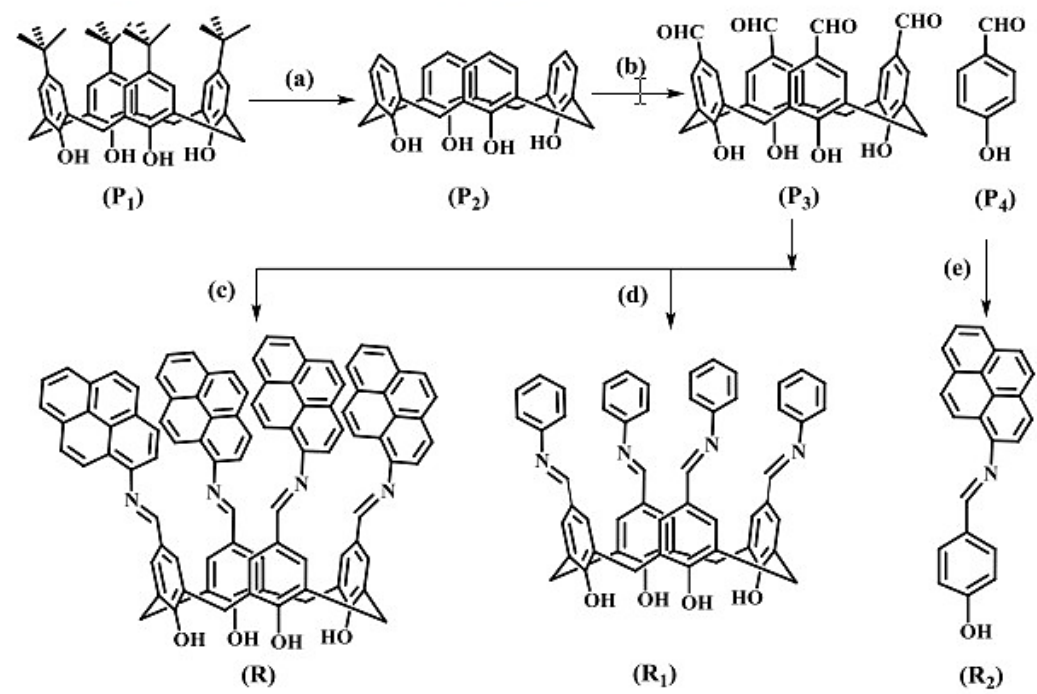

Figure 2. (a) Anhydrous $\mathrm{AlCl}_{3}$, phenol, toluene, stirring at room temperature (RT) for $24 \mathrm{~h}$; (b) hexamethylenetetramine, trifluoroacetic acid, reflux $24 \mathrm{~h}$ and then dil. $\mathrm{HCl}$, stirring at RT for $6 \mathrm{~h}$; (c) 1-amino pyrene, benzoic acid (catalytic amount), toluene, heated at $110^{\circ} \mathrm{C}$ for 5 days; (d) aniline, benzoic acid (catalytic amount), toluene, heated at $110^{\circ} \mathrm{C}$ for 3 days; (e) 1-amino pyrene, benzoic acid (catalytic amount), toluene, heated at $110^{\circ} \mathrm{C}$ for $24 \mathrm{~h}$.

Prata et al. developed a new conjugated polymer (Calix-OCP-PPE (2)) with a main chain phenylene ethynylene interface tethered to Macromolecular receptors based on oxacyclophane-calixarene units and examined its potential uses as a solid-state fluorescence sensing device. Polymer 2 was structurally characterized, and its optical properties in solution and casted films were determined. The ability of polymer 2 to detect two sets of electron acceptor aromatics (NACs and NAs) in the vapor process was explored for demonstration purposes. Thin films of 2 proved to be excellent sensing platforms for sensitive and selective identification of nitroaromatics (2,4-DNT and TNT) and isomeric nitro anilines. The explanations for polymer 2's separate sensing capabilities against these analytes were explored. [36].
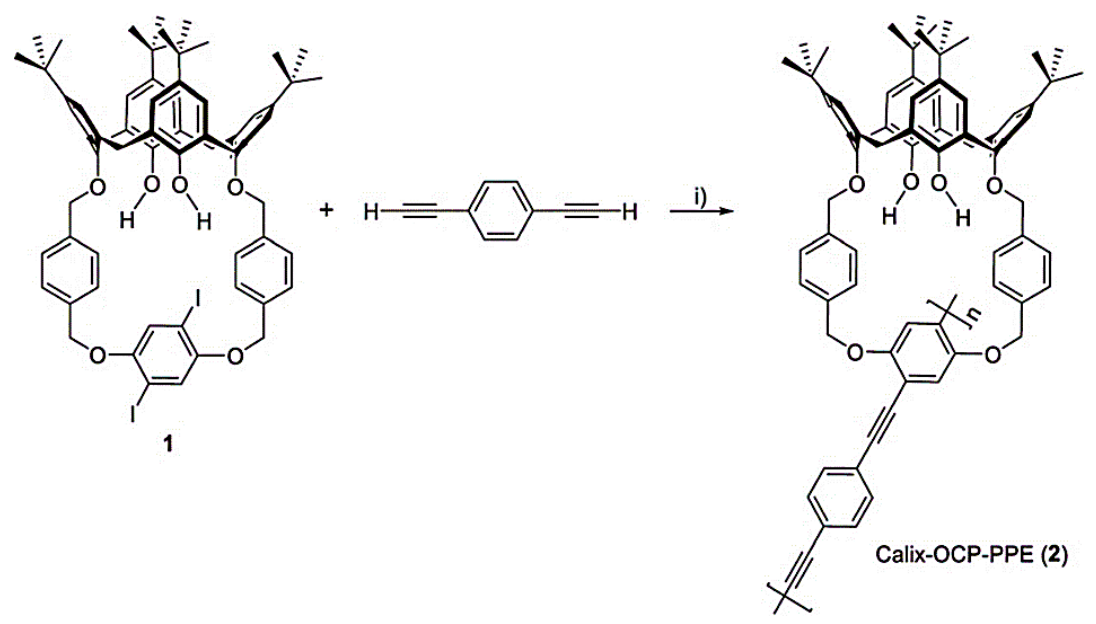

Figure 3. Synthesis of Calix- OCP-PPE (2): (i) $\mathrm{PdCl}_{2}(\mathrm{PPh} 3)_{2}$ and $\mathrm{CuI}$ (catalytic amounts), NEt $3 /$ toluene, $35^{\circ} \mathrm{C}$, $48 \mathrm{~h}$. 
Modi et al. invented a global fluorescent thiacalix[4]arene dinaphthalene sulfonate (TCDNS) by combining thiacalix[4]arene with naphthalene sulfonyl chloride in $2018.1 \mathrm{H}$ NMR, 13C-NMR, and ESI-MS spectrometric measurements were used to classify the TCDNS.

The spectrofluorimetric technique was used to investigate the selectivity of fluoroionophore for 4-nitrotoluene (4-NT) and 2,3-dinitrotoluene (2,3-DNT) among various nitroaromatic compounds (NACs).TCDNS emission is deeply quenched by 4-NT and 2,3DNT. ESI-MS and 1H NMR analysis support the complexation of TCDNS with 4-NT and 2,3DNT. The identification of 4-NT and 2,3-DNT in a water sample was made using a normal addition process. Molecular docking and dynamics simulation techniques have been used to assist the forming of complexes between TCDNS 4-NT and TCDNS 2,3-DNT [1,37-39].

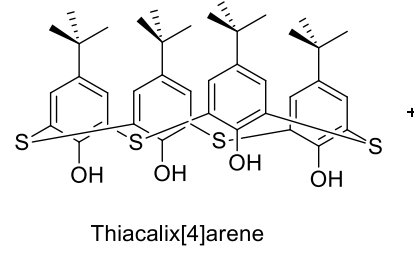

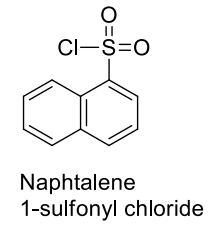

-sulfonyl chloride

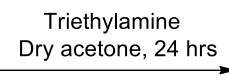

$\stackrel{\text { Dry acetone, } 24 \mathrm{hrs}}{\longrightarrow}$

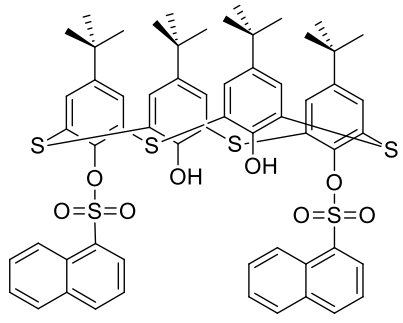

TCDNS

Figure 4. Synthesis of thiacalix[4]arene bis-naphthalene sulfonate.

Jain et al. identified DAQTNOC(5,17-di(N-(9,10-dioxo-9,10-dihydroanthracen- 1yl)acetamide) tetranitrooxacalix[4]arene), a fluorescent oxacalix[4]arene-based receptor for the basic detection of N-methyl-p-nitro aniline (MNA). DAQTNOC, among a variety of grenades, exhibits selective behavior for MNA in the absorption and emission spectra. Furthermore, using docking, molecular dynamics simulations, and time-dependent density functional theory, statistical insights were gained to study the inclusion complex's stability and spectroscopic analysis (TD-DFT). Van der Waals forces and hydrophobic interactions with MNA selectively stabilized DAQTNOC, resulting in a low-energy complex. These results are particularly intriguing because MNA is a well-known insensitive munition that has been observed for the first time using the Oxacalixarenes framework [40-42].

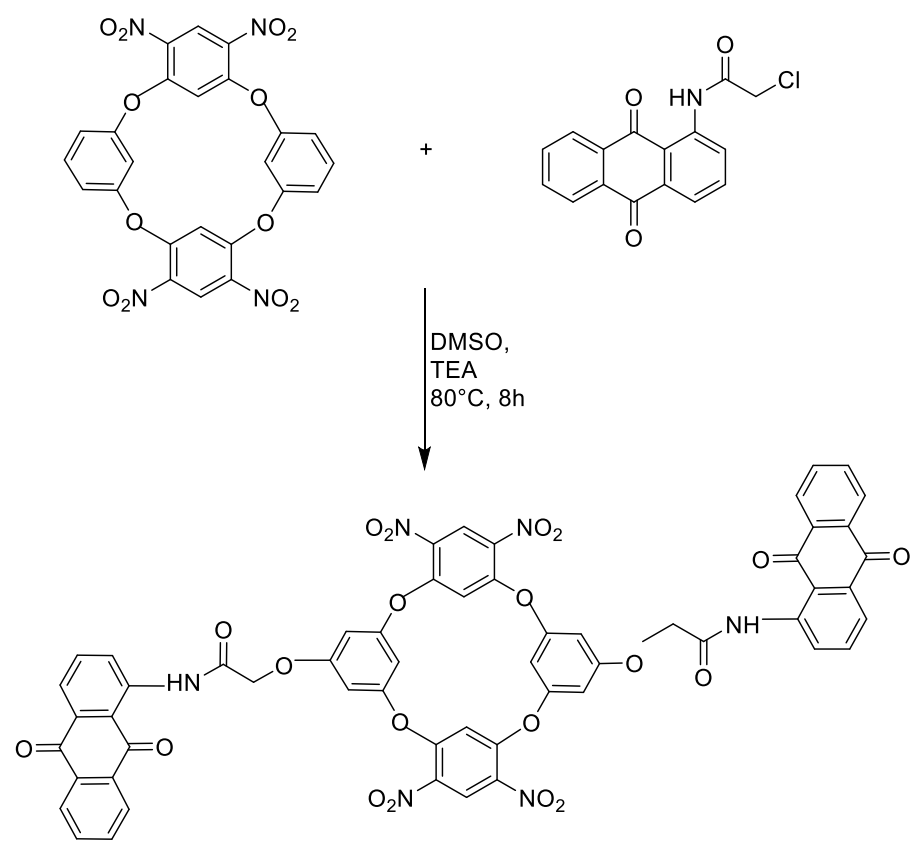

Figure 5. Synthetic route for the preparation of anthraquinone-appended Oxacalix[4]arene. 
Zhan et al. presented tetraphenylethylene (TPE)-based Oxacalixarenes with traditional aggregation-induced emission (AIE) properties, and these Oxacalixarenes demonstrated good detection capability for nitroaromatic explosives [43]. In addition, as a base labile alkylating agent, $\mathrm{N}$-(3-bromopropyl) phthalimide $(\mathrm{N} 3 \mathrm{PPh})$ has been condensed with various organic ligands. $[44,45]$. To achieve a low detection range, sensors based on fluorescence methods are recommended $[46,47]$.

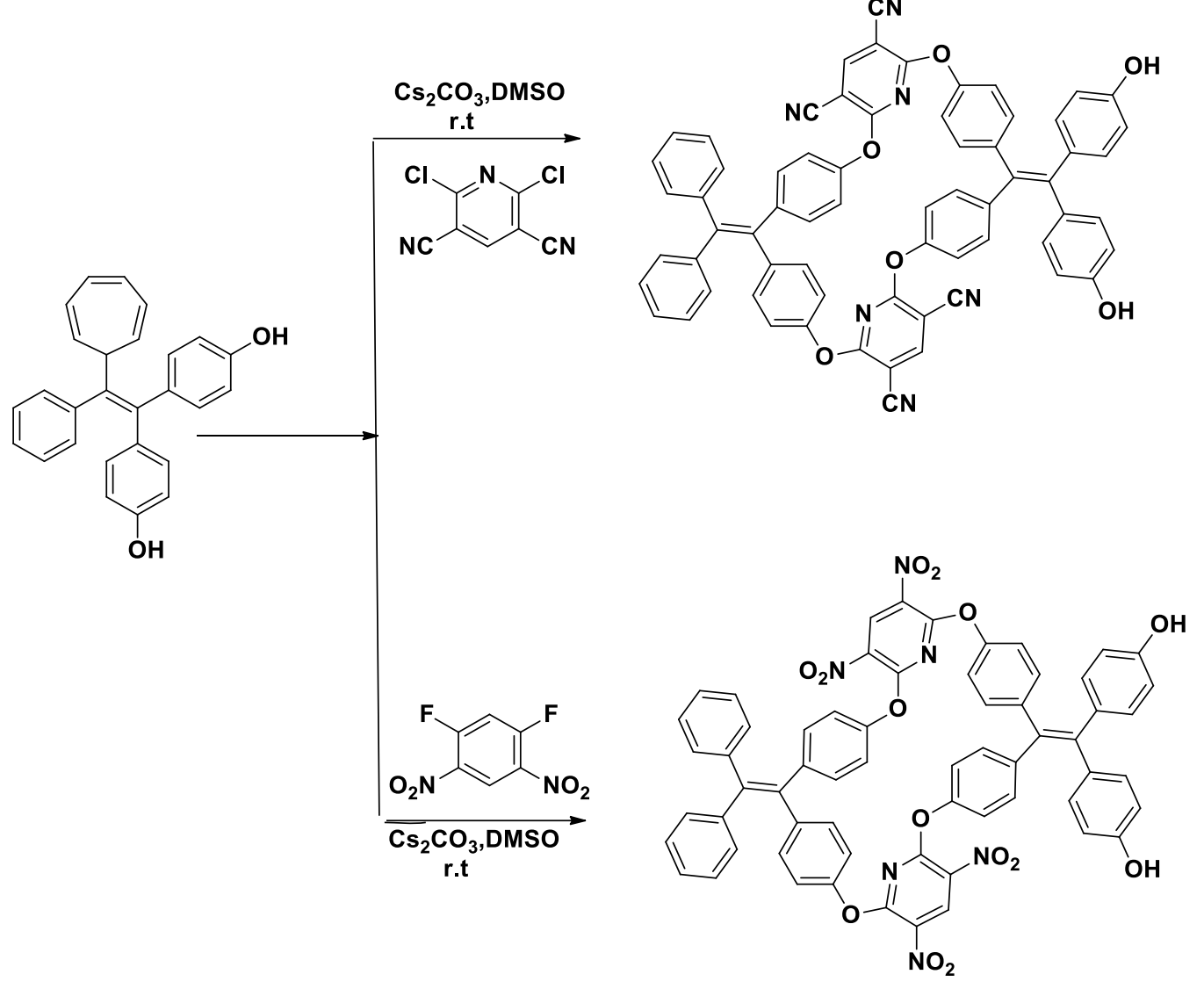

Figure 6. The synthesis of TPE-based Oxacalixarenes $1 \mathrm{a}$ and $1 \mathrm{~b}$.

\section{Conclusions}

This review article focuses on the latest advances, functionalities, synthesis, and architecture of calixarene-based macromolecular systems, as well as their topologies. The synthesis of new calixarene-based macromolecular structures with new functionalities and architecture is still a source of concern for researchers. The most popular identification methods are visual (colorimetric and photoluminescent). The versatility, absence or a low number of incorrect readings, high speed (the test is available in a minute or less), and portability are the main benefits of these techniques. The development of a covalently bonded substance or noncovalently bonded molecular complex between the electron-withdrawing nitro compound (analyte) and the electron-donating chemosensor is the central driving factor in the visual detection of nitroaromatic compounds (explosives) (reagent, sensor, or indicator). This reaction results in an extreme color, static or dynamic fluorescence quenching, and/or an improvement in the sensor's luminescence characteristics, or, in very rare cases, chemosensor photoluminescence enhancement (fluorescence).

In the future, researchers can design new calixarene-based chemosensors having high selectivity, ultra-sensitivity and can test their activity towards various classes of explosives. 


\title{
Funding
}

This research received no external funding.

\section{Acknowledgments}

\begin{abstract}
Acknowledges the Human Resource Development Group-Council of Scientific \& Industrial Research (CSIR), New Delhi, for Research Associate fellowship (File No. 09/070 (0064) 2K19 EMR-I). We gratefully acknowledge the technical support provided by Mehsana Urban Institute of Sciences: Ganpat University to carry out this work at Chemical Research Laboratory: CRL.
\end{abstract}

\section{Conflicts of Interest}

The authors declare no conflict of interest.

\section{References}

1. Modi, K.; Panchal, U.; Patel, C.; Bhatt, K.; Dey, S.; Mishra, D.; Jain, V. Dual in vitro and in silico analysis of thiacalix [4] arene dinaphthalene sulfonate for the sensing of 4-nitrotoluene and 2, 3-dinitrotoluene. New Journal of Chemistry 2018, 42, 2682-2691, https://doi.org/10.1039/C7NJ03820H.

2. Salinas, Y.; Martínez-Máñez, R.; Marcos, M.D.; Sancenón, F.; Costero, A.M.; Parra, M.; Gil, S. Optical chemosensors and reagents to detect explosives. Chemical Society Reviews 2012, 41, 1261-1296, https://doi.org/10.1039/C1CS15173H.

3. Germain, M.E.; Knapp, M.J. Optical explosives detection: from color changes to fluorescence turn-on. Chemical Society Reviews 2009, 38, 2543-2555, https://doi.org/10.1039/B809631G.

4. Martelo, L.M.; Marques, L.F.; Burrows, H.D.; Berberan-Santos, M.N. Explosives detection: From sensing to response. In Fluorescence in Industry, Springer: 2019; 293-320, https://doi.org/10.1007/4243_2019_9.

5. Lee, Y.H.; Liu, H.; Lee, J.Y.; Kim, S.H.; Kim, S.K.; Sessler, J.L.; Kim, Y.; Kim, J.S. Dipyrenylcalix [4] arene-a fluorescence-based chemosensor for trinitroaromatic explosives. Chemistry-A European Journal 2010, 16, 5895-5901, https://doi.org/10.1002/chem.200903439.

6. Steinfeld, J.I.; Wormhoudt, J. Explosives detection: a challenge for physical chemistry. Annual review of physical chemistry 1998, 49, 203-232, https://doi.org/10.1146/annurev.physchem.49.1.203.

7. Hussain, E.; Li, Y.; Cheng, C.; Zhuo, H.; Shahzad, S.A.; Ali, S.; Ismail, M.; Qi, H.; Yu, C. Benzo [ghi] perylene and coronene as ratiometric fluorescence probes for the selective sensing of nitroaromatic explosives. Talanta 2020, 207, 120316, https://doi.org/10.1016/j.talanta.2019.120316.

8. Richter-Torres, P.; Dorsey, A.; Hodes, C. Toxicological profile for 2, 4, 6-trinitrotoluene. Atlanta, GA 1995.

9. Ek, H.; Dave, G.; Sturve, J.; Almroth, B.C.; Stephensen, E.; Förlin, L.; Birgersson, G. Tentative biomarkers for 2, 4, 6-trinitrotoluene (TNT) in fish (Oncorhynchus mykiss). Aquatic toxicology 2005, 72, 221-230. https://doi.org/10.1016/j.aquatox.2005.01.001.

10. Nabeel, F.; Rasheed, T. Rhodol-conjugated polymersome sensor for visual and highly-sensitive detection of hydrazine in aqueous media. Journal of hazardous materials 2020, 388, 121757, https://doi.org/10.1016/j.jhazmat.2019.121757.

11. Rasheed, T.; Li, C.; Nabeel, F.; Qi, M.; Zhang, Y.; Yu, C. Real-time probing of mercury using an efficient "turn-on" strategy with potential as in-field mapping kit and in live cell imaging. New Journal of Chemistry 2018, 42, 10940-10946, https://doi.org/10.1039/C8NJ01746H.

12. Rasheed, T.; Li, C.; Nabeel, F.; Huang, W.; Zhou, Y. Self-assembly of alternating copolymer vesicles for the highly selective, sensitive and visual detection and quantification of aqueous $\mathrm{Hg} 2+$. Chemical Engineering Journal 2019, 358, 101-109, https://doi.org/10.1016/j.cej.2018.09.216.

13. Rasheed, T.; Li, C.; Fu, L.; Nabeel, F.; Yu, C.; Gong, L.; Zhou, Y. Development and characterization of newly engineered chemosensor with intracellular monitoring potentialities and lowest detection of toxic elements. Journal of Molecular Liquids 2018, 272, 440-449, https://doi.org/10.1016/j.molliq.2018.09.112.

14. Rasheed, T.; Li, C.; Bilal, M.; Yu, C.; Iqbal, H.M. Potentially toxic elements and environmentally-related pollutants recognition using colorimetric and ratiometric fluorescent probes. Science of the Total Environment 
2018, 640, 174-193, https://doi.org/10.1016/j.scitotenv.2018.05.232.

15. Rasheed, T.; Li, C.; Zhang, Y.; Nabeel, F.; Peng, J.; Qi, J.; Gong, L.; Yu, C. Rhodamine-based multianalyte colorimetric probe with potentialities as on-site assay kit and in biological systems. Sensors and Actuators B: Chemical 2018, 258, 115-124, https://doi.org/10.1016/j.snb.2017.11.100.

16. Sun, X.; Wang, Y.; Lei, Y. Fluorescence based explosive detection: from mechanisms to sensory materials. Chemical Society Reviews 2015, 44, 8019-8061, https://doi.org/10.1039/C5CS00496A.

17. Hill, H.H.; Simpson, G. Capabilities and limitations of ion mobility spectrometry for field screening applications. Field Analytical Chemistry \& Technology 1997, 1, 119-134, https://doi.org/10.1002/(SICI)1520-6521(1997)1:3<119::AID-FACT2>3.0.CO;2-S.

18. Kumar, R.; Sharma, A.; Singh, H.; Suating, P.; Kim, H.S.; Sunwoo, K.; Shim, I.; Gibb, B.C.; Kim, J.S. Revisiting fluorescent calixarenes: from molecular sensors to smart materials. Chemical reviews 2019, 119, 9657-9721, https://doi.org/10.1021/acs.chemrev.8b00605.

19. Park, S.Y.; Yoon, J.H.; Hong, C.S.; Souane, R.; Kim, J.S.; Matthews, S.E.; Vicens, J. A pyrenyl-appended triazole-based calix [4] arene as a fluorescent sensor for $\mathrm{Cd} 2+$ and $\mathrm{Zn} 2+$. The Journal of organic chemistry 2008, 73, 8212-8218, https://doi.org/10.1021/jo8012918.

20. Gutsche, C.D. Calixarenes: an introduction; Royal Society of Chemistry: 2008.

21. Costa, A.I.; Pinto, H.D.; Ferreira, L.F.; Prata, J.V. Solid-state sensory properties of CALIX-poly (phenylene ethynylene) s toward nitroaromatic explosives. Sensors and Actuators B: Chemical 2012, 161, 702-713, https://doi.org/10.1016/j.snb.2011.11.017.

22. Ganot, N.; Meker, S.; Reytman, L.; Tzubery, A.; Tshuva, E.Y. Anticancer metal complexes: synthesis and cytotoxicity evaluation by the MTT assay. Journal of visualized experiments: JoVE 2013, https://doi.org/10.3791/50767.

23. Lakowicz, J.R. Fluorophores. In Principles of fluorescence spectroscopy, Springer, Boston, MA: 1999; 6393, https://doi.org/10.1007/978-1-4757-3061-6_3.

24. Narayanan, A.; Varnavski, O.; Mongin, O.; Majoral, J.-P.; Blanchard-Desce, M.; Goodson, T. Detection of TNT using a sensitive two-photon organic dendrimer for remote sensing. Nanotechnology 2008, 19, 115502, https://doi.org/10.1088/0957-4484/19/11/115502.

25. Panchal, M.; Kongor, A.; Athar, M.; Modi, K.; Patel, C.; Dey, S.; Vora, M.; Bhadresha, K.; Rawal, R.; Jha, P. Structural motifs of oxacalix [4] arene for molecular recognition of nitroaromatic explosives: Experimental and computational investigations of host-guest complexes. Journal of Molecular Liquids 2020, 306, 112809, https://doi.org/10.1016/j.molliq.2020.112809.

26. Katz, J.L.; Geller, B.J.; Foster, P.D. Oxacalixarenes and oxacyclophanes containing 1, 8-naphthyridines: a new class of molecular tweezers with concave-surface functionality. Chemical communications 2007, 10261028, https://doi.org/10.1039/B615336D.

27. Priego, E.-M.; Camarasa, M.-J.; Pérez-Pérez, M.-J. Efficient synthesis of N-3-substituted 6-aminouracil derivatives via N6-[(dimethylamino) methylene] protection. Synthesis 2001, 2001, 0478-0482, https://doi.org/10.1055/s-2001-11449.

28. Sahin, O.; Yilmaz, M. Synthesis and fluorescence sensing properties of novel pyrene-armed calix [4] arene derivatives. Tetrahedron 2011, 67, 3501-3508, https://doi.org/10.1016/j.tet.2011.03.035.

29. Chopra, R.; Bhalla, V.; Kumar, M.; Kaur, S. Rhodamine appended hexaphenylbenzene derivative: through bond energy transfer for sensing of picric acid. RSC Advances 2015, 5, 24336-24341, https://doi.org/10.1039/C5RA00436E.

30. Dinda, S.K.; Althaf Hussain, M.; Upadhyay, A.; Rao, C.P. Supramolecular sensing of 2, 4, 6-trinitrophenol by a tetrapyrenyl conjugate of calix [4] arene: applicability in solution, in solid state, and on the strips of cellulose and silica gel and the image processing by a cellular phone. ACS omega 2019, 4, 17060-17071, https://doi.org/10.1021/acsomega.9b02855.

31. Wollin, K.-M.; Dieter, H. Toxicological guidelines for monocyclic nitro-, amino-and aminonitroaromatics, nitramines, and nitrate esters in drinking water. Archives of environmental contamination and toxicology 2005, 49, 18-26, https://doi.org/10.1007/s00244-004-0112-2.

32. Dong, M.; Wang, Y.W.; Zhang, A.J.; Peng, Y. Colorimetric and Fluorescent Chemosensors for the Detection of 2, 4, 6-Trinitrophenol and Investigation of their Co-Crystal Structures. Chemistry-An Asian Journal 2013, 8, 1321-1330, https://doi.org/10.1002/asia.201300159.

33. Peng, Y.; Zhang, A.-J.; Dong, M.; Wang, Y.-W. A colorimetric and fluorescent chemosensor for the detection of an explosive-2, 4, 6-trinitrophenol (TNP). Chemical Communications 2011, 47, 4505-4507, https://doi.org/10.1039/C1CC10400D. 
34. Maity, S.; Shyamal, M.; Das, D.; Maity, A.; Dey, S.; Misra, A. Proton triggered emission and selective sensing of 2, 4, 6-trinitrophenol using a fluorescent hydrosol of 2-phenylquinoline. New Journal of Chemistry 2018, 42, 1879-1891, https://doi.org/10.1039/C7NJ03861E.

35. Tanwar, A.S.; Iyer, P.K. Fluorescence "turn-on" indicator displacement assay-based sensing of nitroexplosive 2, 4, 6-trinitrophenol in aqueous media via a polyelectrolyte and dye complex. ACS omega 2017, 2, 44244430, https://doi.org/10.1021/acsomega.7b00765.

36. Prata, J.V.; Costa, A.I.; Teixeira, C.M. A solid-state fluorescence sensor for nitroaromatics and nitroanilines based on a conjugated calix [4] arene polymer. Journal of fluorescence 2020, 30, 41-50, https://doi.org/10.1007/s10895-019-02466-1.

37. Michon, J.; Frelon, S.; Garnier, C.; Coppin, F. Determinations of uranium (VI) binding properties with some metalloproteins (transferrin, albumin, metallothionein and ferritin) by fluorescence quenching. Journal of fluorescence 2010, 20, 581-590, https://doi.org/10.1007/s10895-009-0587-3.

38. Kim, J.S.; Cho, B.; Cho, S.G.; Sohn, H. Silicon quantum dot sensors for an explosive taggant, 2, 3-dimethyl2, 3-dinitrobutane (DMNB). Chemical Communications 2016, 52, 8207-8210, https://doi.org/10.1039/C6CC01341D.

39. Qi, X.; Jin, Y.; Li, N.; Wang, Z.; Wang, K.; Zhang, Q. A luminescent heterometallic metal-organic framework for the naked-eye discrimination of nitroaromatic explosives. Chemical Communications 2017, 53, 10318-10321, https://doi.org/10.1039/C7CC05345B.

40. Mehta, V.; Athar, M.; Jha, P.; Kongor, A.; Panchal, M.; Jain, V. A turn-off fluorescence sensor for insensitive munition using anthraquinone-appended oxacalix [4] arene and its computational studies. New Journal of Chemistry 2017, 41, 5125-5132, https://doi.org/10.1039/C7NJ01111C.

41. Kandpal, M.; Bandela, A.K.; Hinge, V.K.; Rao, V.R.; Rao, C.P. Fluorescence and piezoresistive cantilever sensing of trinitrotoluene by an upper-rim tetrabenzimidazole conjugate of calix [4] arene and delineation of the features of the complex by molecular dynamics. ACS applied materials \& interfaces 2013, 5, 1344813456, https://doi.org/10.1021/am404356v.

42. Boonkitpatarakul, K.; Yodta, Y.; Niamnont, N.; Sukwattanasinitt, M. Fluorescent phenylethynylene calix [4] arenes for sensing TNT in aqueous media and vapor phase. RSC Advances 2015, 5, 33306-33311, https://doi.org/10.1039/C5RA02758F.

43. Khullar, S.; Singh, S.; Das, P.; Mandal, S.K. Luminescent lanthanide-based probes for the detection of nitroaromatic compounds in water. ACS omega 2019, 4, 5283-5292, https://doi.org/10.1021/acsomega.9b00223.

44. Jurcic, M.; Peveler, W.J.; Savory, C.N.; Bučar, D.-K.i.; Kenyon, A.J.; Scanlon, D.O.; Parkin, I.P. Sensing and discrimination of explosives at variable concentrations with a large-pore MOF as part of a luminescent array. ACS applied materials \& interfaces 2019, 11, 11618-11626, https://doi.org/10.1021/acsami.8b22385.

45. Yu, C.; Sun, X.; Zou, L.; Li, G.; Zhang, L.; Liu, Y. A pillar-layered Zn-LMOF with uncoordinated carboxylic acid sites: high performance for luminescence sensing Fe3+ and TNP. Inorganic chemistry 2019, 58, 40264032, https://doi.org/10.1021/acs.inorgchem.9b00204.

46. Bhatt, K.D.; Shah, H.D.; Modi, K.M.; Narechania, M.B.; Patel, C. Calix [4] pyrrole virtuous sensor: a selective and sensitive recognition for $\mathrm{Pb}$ (II) ions by spectroscopic and computational study. Supramolecular Chemistry 2019, 31, 268-282, https://doi.org/10.1021/acs.inorgchem.9b00204.

47. Pomal, N.C.; Bhatt, K.D.; Modi, K.M.; Desai, A.L.; Patel, N.P.; Kongor, A.; Kolivoška, V. Functionalized Silver Nanoparticles as Colorimetric and Fluorimetric Sensor for Environmentally Toxic Mercury Ions: An Overview. Journal of fluorescence 2021, 1-15, https://doi.org/10.1007/s10895-021-02699-z. 